\title{
Motor and cognitive decline of healthy elderly and elderly with parkinson's disease - a cross-sectional study
}

\author{
Wildja de Lima Gomes', Neildja Maria da Silva', Laize Gabriele Castro Silva', Ênio Walker Azevedo Cacho', \\ Roberta de Oliveira Cacho', Maria do Socorro Luna Cruz1, Núbia Maria Freire Vieira Lima1
}

\begin{abstract}
Background: Parkinson's disease (PD) was initially described as a movement disorder, however there is now recognition that its clinical features also include non-motor symptoms such as cognitive impairment and dementia, which are frequent even in the early stages of the disease and, especially in the advanced stages. Cognitive deficits in PD include impairments in executive functions, attention, memory, and visuospatial skills. Cognitive impairment may manifest as mild cognitive impairment $(\mathrm{MCl})$ or dementia, in which $\mathrm{MCl}$ refers to the stage between normal cognitive functioning and dementia. Factors associated with cognitive dysfunction in PD include advanced age, low schooling, worse motor scores, stiffness, postural instability and increased daytime sleepiness. Objective: To track cognitive decline and to correlate measurement instruments in subjects with PD by comparing them to healthy subjects. Methods: Study conducted at the Faculty of Health Sciences of Trairi / UFRN. The sample consisted of 20 old people (10 healthy elderlies and 10 elderlies with PD). It was applied the socio-demographic record, Unified Parkinson's Disease Rating Scale (UPDRS II and III), Hoehn \& Yahr Scale, Mini Mental State Examination, Leganés Cognitive Test (LCT) and Montreal Cognitive Assessment (MoCA). Results: It was observed cognitive decline in both groups by MoCA ( $90 \%$ of the PD group and $80 \%$ of the healthy group), with no statistically significant difference ( $p=0.10)$. It was also verified association between UPDRS II and LCT $(r=-0.69, p=0.03)$ and between UPDRS III and LCT $(r=-0.66, p=0.04)$. Conclusion: We found a cognitive deficit in the elderly group with PD, with no significant difference when compared to the healthy elderly. There was an association between motor and cognitive function in subjects with PD. MoCA was more sensitive in the screening of cognitive deficit in subjects with PD.
\end{abstract}

Keywords: Parkinson's Disease; Geriatrics; Cognition; Education.

\section{INTRODUCTION}

Parkinson's disease (PD) was initially described as a movement disorder, however there is now recognition that its clinical features also include non-motor symptoms such as cognitive impairment and dementia, which are frequent even in the early stages of the disease and, especially in the advanced stages. Cognitive deficits in PD include impairments in executive functions, attention, memory, and visuospatial skills ${ }^{(1)}$. Cognitive impairment may manifest as mild cognitive impairment $(\mathrm{MCl})$ or dementia, in which $\mathrm{MCl}$ refers to the stage between normal cognitive functioning and dementia(2). Patients with PD compared to healthy subjects have a greater risk, between 24 and 31\%, of developing dementia ${ }^{(3)}$. Factors associated with cognitive dysfunction in PD include advanced age, low schooling, worse motor scores, stiffness, postural instability and increased daytime sleepiness ${ }^{(4)}$. Dementia is recognized as a late characteristic in PD, subtle cognitive dysfunction usually occurs early in the disease, so that subjects without quantifiable cognitive dysfunction do not meet the dementia criteria and are defined with $\mathrm{MCl}^{(5)}$. Considering the existence of cognitive deficits in PD during clinical practice, it is usually not feasible to perform comprehensive neuropsychological assessments, in these situations, the availability of short, simple and viable cognitive screening through screening instruments of cognitive impairment is quite effective. Several screening tests, including the Mini Mental State Examination (MMSE) and the Montreal Cognitive Assessment (MoCA) have been reported to be useful for this purpose in patients with $\mathrm{PD}^{(6)}$. The MMSE and MoCA evaluation instruments are validated and widely used in the cognitive evaluation of subjects with PD in Brazil, but the Leganés Cognitive Test (LCT) has not yet been applied in a Brazilian sample with $P D^{(7)}$. In Activities of daily living (ADL's), the ability to perform two or more tasks simultaneously is essential, since subjects with PD may present difficulties in accomplishing two tasks (motor and cognitive tasks). It is extremely important the cognitive evaluation in these patients to establish and appropriately guide the physiotherapeutic behaviors, whose main objective is to make them functional to 
perform ADL's independently and autonomously. It should be considered treatments with a holistic approach, focusing not only on motor functions but an in effective therapy according to individual cognitive performance, positively impacting the quality of this population. Therefore, the aim of the present study was to track cognitive decline and to correlate the instruments of measurement of cognitive and motor functions in subjects with PD, comparing them to healthy subjects.

\section{METHODS}

This is a descriptive, comparative, cross-sectional, analytical and non-interventional study conducted at the Clinical School of Physiotherapy and at the Laboratory of Human Motricity of the School of Health Sciences of the Trairi (FACISA), Federal University of the Rio Grande do Norte (UFRN). The study was approved by the Research Ethics Committee of the institution, with number 901.372 . The study sample is the result of a non-probability sampling method, convenience sampling. Subjects with PD were recruited from a waiting list of the Clinical School of Physiotherapy and the elderly were recruited from a basic health unit of the same municipality. The inclusion criteria adopted for the group with PD were aged between 50 and 80 years, with recent or late clinical diagnosis of the disease, using specific medication for PD. These subjects should be in the phase of the drug action, period between 50 and 120 minutes $^{(8)}$, after ingestion of the medicine. Subjects with parkinsonian syndrome and / or other neurological comorbidities (cognitive impairment due to traumatic brain injury, stroke and, brain tumor) were excluded. For the elderly group, the inclusion criteria adopted were aged between 60 and 80 years and were excluded elderly with a history of neurological diseases.

\section{Assessment tools and procedures}

Subjects who met the inclusion criteria of both groups signed the Free and Informed Consent Form, and were then referred to an evaluation room to fill out the socio-demographic data sheet, with data relevant for evaluation. The following assessment instruments were then applied: Unified Assessment Scale for Parkinson's Disease, Modified Hoehn and Yahr Staging Scale, Mini Mental State Examination, Leganès Cognitive Test, and Montreal Cognitive Assessment.

Unified Parkinson's Disease Rating Scale (UPDRS)(9) presents 42 items, divided into mental activity, behavior and mood, ADL's, motor examination and complications of drug therapy, higher scores indicate greater clinical impairment. The ADL's and motor examination (sections II and III) were used, with total scores of 52 and 56, respectively. Modified Hoehn and Yahr Staging Scale $(\mathrm{HY})^{(10)}$ was used to indicate the general state and level of disability of the patients with PD. Subjects classified in stages I, II and III have mild to moderate disability, while those in stages IV and $\mathrm{V}$ present severe disability. The most recent version of the HY was used, which includes intermediary stages ${ }^{(11)}$. The MMSE assess the cognitive function ${ }^{(12)}$. The score ranges from 0 to 30 points, with different cutoffs for different levels of schooling, namely: 13 for illiterate, 18 for low and medium schooling and 26 for high schooling. The score 30 represents preserved cognitive function $^{(13)}$. The LCT is an easily applicable cognitive screening test with no school impact on its final scores ${ }^{(14)}$. The total score varies from 0 to 32 points (worse and better cognitive function, respectively) and the cutoff point for cognitive deficit is 22 points ${ }^{(15 ; 16)}$. The MoCA is a tool for screening for mild cognitive impairment in which the total score is 30 points, and a satisfactory cognitive function is considered the score of 21 for patients with PD ${ }^{(17)}$ and 25 for healthy elderly, a point is added if the subjects has less than 12 years of schooling ${ }^{(18)}$. A single evaluation session per subject was conducted, with a mean duration of 60 minutes, with a 5-minute rest period between the tests. The evaluation of the patients with PD was performed at the time of the medication and was evaluated with all the mentioned measurement instruments. The elderly subjects were evaluated only by the socio-demographic record, MMSE, LCT and MoCA.

\section{Statistical analysis}

A normal distribution of the variables was observed by the Shapiro-Wilk test. Descriptive analysis of the quantitative and categorical variables of the groups were performed and expressed in frequency, percentage, mean and standard deviation. The t-test for independent samples was used to compare the quantitative variables between the groups; Fisher's exact test for comparison of the frequency of nominal variables between groups; and the Pearson test to verify association of variables of the same group, according to the classification of the correlation coefficient: $0-0.25$ very low; 0.26-0.49 low; 0.50-0.69 moderate; 0.70-0.89 elevated; 0.90-1.00 very high ${ }^{(19)}$. Values of $p<0.05$ were considered as statistically significant. It was used the Statistical Package for the Social Sciences (SPSS Inc., Chicago, USA), version 20.0 for Windows.

\section{RESULTS}

The initial sample consisted of 36 subjects and, of this sample, 22 patients were included in the PD group, but 12 were excluded, since 1 had no medical diagnosis, 1 did not answer the calls and 10 refused to participate in the study. From the initial sample, 14 subjects were included in the elderly group, however 2 were excluded because they were older than the proposed in the study and 2 were excluded because they had neurological comorbidities. Totalizing 10 subjects in the PD group and 10 in the healthy elderly group. Table 1 shows the variables age, gender, schooling and demographic data of both groups. The distribution of PD staging is shown in table 2 , and in table 3 is shown the summary of the assessment instruments for both groups and the frequency with scores below the 
Table 1. Demographic data of subjects with Parkinson's disease and healthy elderly.

\begin{tabular}{|c|c|c|c|c|c|}
\hline \multirow{2}{*}{ Variables } & \multicolumn{2}{|c|}{ PD Group } & \multicolumn{2}{|c|}{ Healthy Group } & \multirow{2}{*}{ p-value } \\
\hline & n (\%) & mean $\pm S D$ & n (\%) & mean $\pm S D$ & \\
\hline Age (years) & & $68.0 \pm 12.1$ & & $61.3 \pm 5.8$ & 0.13 \\
\hline Gender (F/M) & $4 / 6(40 \% / 60 \%)$ & & $7 / 3(70 \% / 30 \%)$ & & 0.19 \\
\hline Schooling & & $8.00 \pm 4.05$ & & $9.70 \pm 2.49$ & 0.27 \\
\hline PD diagnosis time & & $7.4 \pm 4.35$ & & & \\
\hline
\end{tabular}

Note: $P D=$ Parkinson's Disease; $S D=$ standard deviation; $n=$ sample number; $F=$ female; $M=$ male; $p$-value: $<0.05$.

Table 2. Hoehn \& Yahr Staging Scale.

\begin{tabular}{lc}
\hline \multicolumn{1}{c}{ Characteristics } & $\begin{array}{c}\text { Parkinson } \\
\text { Disease Group }\end{array}$ \\
\hline Stage $\mathbf{0}$ No sign of the disease & $0 \%$ \\
Stage $\mathbf{1}$ Unilateral disease & $0 \%$ \\
Stage $\mathbf{1 . 5}$ Unilateral and axial involvement & $20 \%$ \\
Stage $\mathbf{2}$ Bilateral disease without balance deficit & $10 \%$ \\
Stage $\mathbf{3}$ Mild to moderate bilateral disease; some & $30 \%$ \\
postural instability; ability to live independently & \\
$\begin{array}{l}\text { Stage } \mathbf{4} \text { Severe disability, still able to walk and stand } \\
\text { without assistance }\end{array}$ & $30 \%$ \\
$\begin{array}{l}\text { Stage } \mathbf{5} \text { Confined to bed or wheelchair. Need } \\
\text { assistance }\end{array}$ & $10 \%$ \\
\hline
\end{tabular}

Table 3. Assessment instruments of subjects with Parkinson's disease and healthy elderly.

\begin{tabular}{ccccc}
\hline \multirow{2}{*}{ Variables } & PD Group $(\mathrm{n}=10)$ & & Healthy Group $(\mathrm{n}=10)$ & \\
\cline { 2 - 2 } & Mean \pm SD or $n$ & & Mean \pm SD or $n$ & \\
\hline MMSE & $21.0 \pm 5.75$ & & $24.2 \pm 3.85$ & 0.16 \\
LCT & $22.4 \pm 6.44$ & & $25.6 \pm 3.40$ & 0.18 \\
MoCA & $13.9 \pm 7.37$ & & $18.8 \pm 5.47$ & 0.1 \\
UPDRS II & $16.1 \pm 7.83$ & & & \\
UPDRS III & $18.2 \pm 10.2$ & & \\
\hline
\end{tabular}

Note: $\mathrm{PD}=$ Parkinson's disease; UPDRS= Unified Assessment Scale for Parkinson's Disease; $\mathrm{HY}=$ Hoehn \& Yahr; MMSE= Mini-Mental State Examination; LCT= Leganès Cognitive Test; $\mathrm{MoCA}=$ Montreal Cognitive Assessment; $\mathrm{SD}=$ standard deviation; $\mathrm{n}=$ sample number; *comparison between independent samples by independent t-test or Fisher's exact test.

cut-off point of the cognitive instruments. The correlation coefficients between the measurement instruments applied in the PD group are in table 4. Figure 1 shows the frequency of both groups with scores below the cut-off point by measuring instruments.

\section{DISCUSSION}

With the accomplishment of this study, a decline of cognitive function was observed in the PD group and healthy elderly, especially by the MoCA instrument, however, with no statistically significant difference. Also, it was verified a significant linear correlation between performance in ADL's

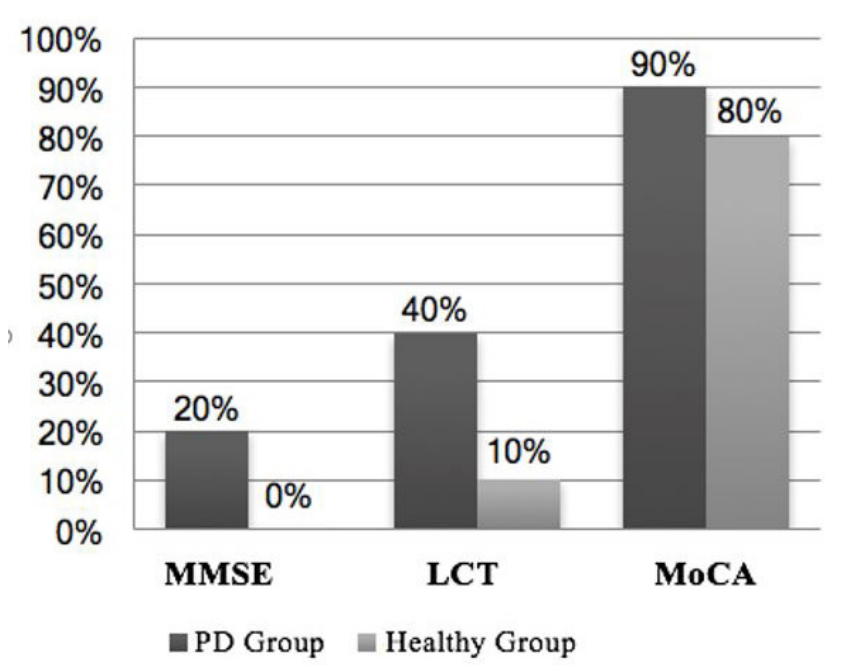

Figure 1. Frequency of subjects with cognitive decline in both groups according to each assessment instrument frequency of subjects below the cutoff point. Note: $P D=$ Parkinson's disease; $M M S E=$ Mini-Mental State Examination; LCT= Leganès Cognitive Test; MoCA= Montreal Cognitive Assessment.

and motor activity with cognitive function measured by the LCT. Despite the lack of statistical significance, there is a clinical significance in the frequency of cognitive impairment in PD tracked by MoCA, which may be justified by the low to moderate level of formal schooling in both groups. To Pfeiffer et al. ${ }^{(4)}$, the factors associated with cognitive dysfunction in PD include advanced age, low schooling, worse motor scores, stiffness, postural instability and increased daytime sleepiness. Considering the factors associated with cognitive decline, 671 patients with PD were evaluated and 235 presented cognitive decline through MoCA, associated with advanced age, lower level of schooling, higher motor impairment by UPDRS, and more advanced stages according to $\mathrm{Hy}^{(20)}$. Another possible factor associated with cognitive decline is the worse motor scores ${ }^{(4)}$, verified in this study by the scores of sections II and III of the UPDRS, besides to the moderate to severe motor impairment of subjects with PD, as observed by the HY. In addition, in this study, was found an association between LCT and UPDRS II and III scores, but no association between LCT and HY. In this sense, Sobreira et al $^{(17)}$, evaluated 79 patients with PD to measure mild cognitive decline and dementia using MoCA and observed that subjects 
Table 4. Pearson correlation between instruments of evaluation of the group of patients with Parkinson's disease.

\begin{tabular}{|c|c|c|c|c|c|c|}
\hline Variables & UPDRS II & UPDRS III & HY & MMSE & LCT & MoCA \\
\hline UPDRS II & & & $\begin{array}{l}r=0.87 \\
p=0.001\end{array}$ & $\begin{array}{l}r=-0.53 \\
p=0.11\end{array}$ & $\begin{array}{l}r=-0.69 \\
p=0.03\end{array}$ & $\begin{array}{l}r=-0.26 \\
p=0.45\end{array}$ \\
\hline UPDRS III & $\begin{array}{l}r=0.91 \\
p<0.001\end{array}$ & & $\begin{array}{l}r=0.84 \\
p=0.002\end{array}$ & $\begin{array}{l}r=-0.60 \\
p=0.07\end{array}$ & $\begin{array}{l}r=-0.66 \\
p=0.04\end{array}$ & $\begin{array}{l}r=-0.32 \\
p=0.36\end{array}$ \\
\hline HY & $\begin{array}{l}r=0.87 \\
p<0.001\end{array}$ & $\begin{array}{l}r=0.84 \\
p=0.002\end{array}$ & ----- & $\begin{array}{l}r=-0.28 \\
p=0.431\end{array}$ & $\begin{array}{l}r=-0.54 \\
p=0.11\end{array}$ & $\begin{array}{l}r=-0.04 \\
p=0.89\end{array}$ \\
\hline MMSE & $\begin{array}{l}r=-0.53 \\
p=0.11\end{array}$ & $\begin{array}{l}r=-0.60 \\
p=0.07\end{array}$ & $\begin{array}{l}r=-0.28 \\
p=0.43\end{array}$ & & $\begin{array}{l}r=0.75 \\
p<0.001\end{array}$ & $\begin{array}{l}r=0.86 \\
p<0.001\end{array}$ \\
\hline LCT & $\begin{array}{l}r=-0.69 \\
p=0.03\end{array}$ & $\begin{array}{l}r=0.66 \\
p=0.04\end{array}$ & $\begin{array}{r}r=-0.54 \\
p=0.11\end{array}$ & $\begin{array}{l}r=0.75 \\
p<0.001\end{array}$ & & $\begin{array}{l}r=0.72 \\
p<0.001\end{array}$ \\
\hline MoCA & $\begin{array}{l}r=-0.26 \\
p=0.45\end{array}$ & $\begin{array}{l}r=-0.32 \\
p=0.36\end{array}$ & $\begin{array}{l}r=-0.04 \\
p=0.89\end{array}$ & $\begin{array}{c}r=0.86 \\
p<0.001\end{array}$ & $\begin{array}{c}r=0.72 \\
p<0.001\end{array}$ & \\
\hline
\end{tabular}

Note: $P D=$ Parkinson's disease; UPDRS= Unified Assessment Scale for Parkinson's Disease; HY= Hoehn \& Yahr; MMSE= Mini-Mental State Examination; LCT= Leganès Cognitive Test; MoCA= Montreal Cognitive Assessment; $r=$ Pearson correlation coefficient.

with dementia were more compromised in motor aspects and had the most advanced disease according to the HY scale. We highlight the association between cognitive and motor function found in this study, considering that one of the consequences of cognitive decline is the inability to plan, start and monitor the sequenced behavior related to one or more objectives, which, given the new information, should be reformulated $^{(21)}$. In this way, cognitive decline may impair the ability to cope with double or multiple tasks of subjects with PD and, consequently, increase the risk of falls, as compared to healthy elderly ${ }^{(22)}$. Thus, screening for cognitive decline in PD will guide and ensure the implementation of dual motor and cognitive task training programs for this condition.

The MMSE is used extensively in $\mathrm{PD}^{(23-25)}$ and assesses mainly memory and language skills. The scientific literature indicates that MMSE may not be sensitive to detect many cases of mild cognitive impairment ${ }^{(18)}$. In contrast, MoCA is a cognitive screening tool that was designed to address some of the limitations of MMSE as it evaluates a broader range of cognitive domains and is more challenging from a cognitive global point of view ${ }^{(16)}$. Consistent with this information, in this study the MoCA detected a larger number of subjects with cognitive impairment. Memória et al. ${ }^{(26)}$ validated the Brazilian version of the MoCA through the examination of 112 healthy or cognitive deficient elderly subjects and defined the cut-off point of 25 for indication of cognitive impairment. On the other hand, Sobreira et $a^{(17)}$, evaluated the accuracy of the Brazilian version of MoCA in 79 patients with PD and suggested a cutoff point of 21 for this population, pointing out that MoCA is a useful tool to evaluate early cognitive decline in PD. Chou et al. ${ }^{(24)}$ examined 49 subjects with PD with 5.8 years of mean disease time and found MMSE with a mean score of 29.1 points and MoCA with 25.8 points, elevated scores compared to the findings of the present study. However, among the 49 subjects, $45 \%$ were below the cut-off point of
MMSE and 95.9\% showed a cognitive deficit by MoCA, similar to the frequency of patients with cognitive decline found in this study. In Brazil, the MMSE and MoCA instruments were used by Macuglia, et al. ${ }^{(22)}$ with the objective of investigating cognitive function in healthy adults with PD. It was verified that the PD group presented greater cognitive impairment in relation to the healthy group by applying MMSE $(m=22.2$, $s d=3.47)$ and MoCA $(m=14.6, s d=4.60)$, results similar to those of the PD group in the present study.

There is no Brazilian or international antecedent of the use of LCT for the evaluation of PD. Knowing that the MoCA is not appropriate for evaluation of subjects with low schooling since it requires at least 4 years of formal study, and that the MMSE considers changes in the cutoff point according to schooling, Zunzunegui et al. ${ }^{(14)}$ made the use of LCT useful for this study, since the conclusion of this instrument does not depend on the ability to write, calculate, draw or carry out abstract thinking, favoring adequate cognitive screening in low education populations, in counterpoint of MMSE and MoCA instruments. Thus, it is suggested that the LCT is used to investigate cognitive dysfunction of patients with PD, especially low level of education. In addition, despite the cognitive scales LCT, MMSE and MoCA showed a significant correlation between them, LCT was the only instrument to measure cognitive function that correlated with the motor scores of UPDRS II and III.

The limitations of this study are related to the late clinical and physiotherapeutic diagnosis of these subjects due to the reduced reach of this multiprofessional health team, namely, neurologists, geriatricians, physiotherapists, nutritionists, nurses, psychologists and other professionals; and the cross-sectional design of the study, which did not allow overtime evaluations and observation of the behavior of the cognitive decline found in the sample. 


\section{CONCLUSION}

The Mini Mental State Examination, Leganès Cognitive Examination and Montreal Cognitive Evaluation instruments detected cognitive impairment in subjects with Parkinson's Disease. Among these instruments LCT seems to favor adequate cognitive screening in samples with low formal schooling. There was an association between motor function (daily life and motor activity) and cognitive function (scores of the LCT) in subjects with Parkinson's Disease.

\section{AUTHORS' CONTRIBUTION}

WLG: intellectual content of this work (ICMJE guidelines); critical review; revising the intellectual content of the manuscript before the final presentation. NMS and LGCS: intellectual content of this work (ICMJE guidelines); data collection and treatment; literature survey; analysis/interpretation; writing of the manuscript. EWAC, ROC, MSLC and NMFVL: intellectual content of this work (ICMJE guidelines); development and methodological design; critical review.

\section{CONFLICTS OF INTEREST}

The authors declare that there was no conflict of interests.

\section{REFERENCES}

1. Calleo J, Burrows C, Levin H, Marsh L, Lai E, York M. Cognitive Rehabilitation for Executive Dysfunction in Parkinson's Disease: Application and Current Directions. Parkinson's Disease. 2012;2012:1-6.

2. Reid W, Hely M, Morris J, Loy C, Halliday G. Dementia in Parkinson's disease: a 20-year neuropsychological study (Sydney Multicentre Study). Journal of Neurology, Neurosurgery \& Psychiatry. 2011;82(9):1033-1037.

3. Pagonabarraga J, Kulisevsky J. Cognitive impairment and dementia in Parkinson's disease. Neurobiology of Disease. 2012;46(3):590-596.

4. Pfeiffer H, Løkkegaard A, Zoetmulder M, Friberg L, Werdelin L. Cognitive impairment in early-stage non-demented Parkinson's disease patients. Acta Neurologica Scandinavica. 2013;129(5):307-318.

5. Aarsland D, Bronnick K, Larsen J, Tysnes O, Alves G. Cognitive impairment in incident, untreated Parkinson disease: The Norwegian ParkWest Study. Neurology. 2008;72(13):1121-1126.

6. Hoops S, Nazem S, Siderowf A, Duda J, Xie S, Stern M et al. Validity of the MoCA and MMSE in the detection of $\mathrm{MCl}$ and dementia in Parkinson disease. Neurology. 2009;73(21):1738-1745.

7. Almeida I, Bueno $\mathrm{M}$, Andrello A, Batistetti C, Lemes L, Barboza $\mathrm{N}$ et al. Fisioterapia baseada no treinamento de dupla tarefa no equilíbrio de indivíduos com doença de Parkinson. Saúde (Santa Maria). 2015;41(2).

8. Lescano S. Investigação de queixa específica de deglutição para medicamentos em pacientes com diagnóstico de doença de Parkinson [Graduação]. Universidade Federal do Rio Grande do Sul; 2013.

9. Fahn S, Marsden C, Van Woert M. Myoclonus. New York: Raven Press; 1986.

10. Hoehn M, Yahr M. Parkinsonism: Onset, progression, and mortality. Neurology. 1998;50(2):318.

11. Schenkman M, Clark K, Xie T, Kuchibhatla M, Shinberg M, Ray L. Spinal Movement and Performance of a Standing Reach Task in Participants With and Without Parkinson Disease. Physical Therapy. 2001;81(8):1400-1411
12. Burns A, Brayne C, Folstein M. Key Papers in Geriatric Psychiatry: minimental state: a practical method for grading the cognitive state of patients for the clinician. M. Folstein, S. Folstein and P. McHugh,Journal of Psychiatric Research, 1975,12, 189-198.

13. Bertolucci P, Brucki S, Campacci S, Juliano Y. O Mini-Exame do Estado Mental em uma população geral: impacto da escolaridade. Arquivos de Neuro-Psiquiatria. 1994;52(1):01-07.

14. Zunzunegui M, Gutiérrez Cuadra P, Béland F, Del Ser T, Wolfson C. Development of simple cognitive function measures in a community dwelling population of elderly in Spain. International Journal of Geriatric Psychiatry. 2000;15(2):130-140.

15. Caldas V, Zunzunegui M, Freire A, Guerra R. Translation, cultural adaptation and psychometric evaluation of the Leganés cognitive test in a low educated elderly Brazilian population. Arquivos de Neuro-Psiquiatria. 2012;70(1):22-27

16. Nasreddine Z, Phillips N, Badirian V, Charbonneau S, Whitehead V, Collin I et al. The Montreal Cognitive Assessment, MoCA: A Brief Screening Tool For Mild Cognitive Impairment. Journal of the American Geriatrics Society. 2005;53(4):695-699.

17. Sobreira E, Pena-Pereira M, Eckeli A, Sobreira-Neto M, Chagas M, Foss $M$ et al. Screening of cognitive impairment in patients with Parkinson's disease: diagnostic validity of the Brazilian versions of the Montreal Cognitive Assessment and the Addenbrooke's Cognitive ExaminationRevised. Arquivos de Neuro-Psiquiatria. 2015;73(11):929-933.

18. Zadikoff C, Fox S, Tang-Wai D, Thomsen T, de Bie R, Wadia P et al. A comparison of the mini mental state exam to the montreal cognitive assessment in identifying cognitive deficits in Parkinson's disease. Movement Disorders. 2007;23(2):297-299.

19. Munro B, Plichta S, Kelvin E. Munro's statistical methods for health care research. Philadelphia, PA: Wolters Kluwer, Lippincott Williams \& Wilkins; 2013.

20. Ling C, Cuiyu Y, Xiaosu F, Weiguo L, Ping H, Ning Z, Shenghan K. Using the Montreal Cognitive Assessment Scale to screen for dementia in Chinese patients with Parkinson's disease. Shanghai Arch Psychiatry. 2013 Oct; 25(5):296-305.

21. Baggio J, Curtarelli M, Rodrigues G, Tumas V. Validity of the Brazilian version of the freezing of gait questionnaire. Arquivos de NeuroPsiquiatria. 2012;70(8):599-603.

22. Macuglia G, Rieder C, Trentini L, Filho N, Moraes A, Almeida R. Comprometimento Executivo nas Fases Leve à Grave da Doença de Parkinson. Psico. 2015;46(2):198.

23. Chou K, Lenhart A, Koeppe R, Bohnen N. Abnormal MoCA and normal range MMSE scores in Parkinson disease without dementia: Cognitive and neurochemical correlates. Parkinsonism \& Related Disorders. 2014;20(10):1076-1080

24. Lucza T, Karádi K, Kállai J, Weintraut R, Janszky J, Makkos A et al. Screening Mild and Major Neurocognitive Disorders in Parkinson's Disease. Behavioural Neurology. 2015;2015:1-10

25. Kim J, Sunwoo M, Sohn Y, Lee P, Hong J. The MMSE and MoCA for Screening Cognitive Impairment in Less Educated Patients with Parkinson's Disease. Journal of Movement Disorders. 2016;9(3):152-159.

26. Memória C, Yassuda M, Nakano E, Forlenza O. Brief screening for mild cognitive impairment: validation of the Brazilian version of the Montreal cognitive assessment. International Journal of Geriatric Psychiatry. 2012;28(1):34-40. 